\title{
Bid to expand horizon of medical students fails
}

$\mathrm{T}$ he vote was so close it drew a collective "ooh" from the crowd. The speaker running the vote said it was the closest he had ever seen. Unfortunately for Dr. Roona Sinha - who on Aug. 24 at the Canadian Medical Association's 144th annual general meeting in St. John's, Newfoundland and Labrador seconded a motion to support the inclusion of global health training in the core curriculum of medical education - the result was not in her favour. Perhaps the reason only $48 \%$ of delegates supported the motion, and $49 \%$ opposed it, can be chalked up to a misunderstanding.

"A lot of people didn't understand what we meant by global health," says Sinha. "We need to do education even in the physician group. Global health is not only about students that go on international electives, but it's also about addressing problems within our own marginalized populations and in underserved areas."

Indeed, the issues she faced during a trip to Uganda were similar to those she saw on a visit to Nunavut, says Sinha, a pediatrics resident in British Columbia. "A lot of these issues are cross-cultural. How do you care for kids if you have limited resources? Do you put your money toward feeding a child or their medical needs? What do you do with one of your children if another one is sick? How do you deal with family problems related to alcohol?"

Medical students who wish to work for a period in other countries often have to educate themselves on cultural barriers they may encounter. Dr. Rhett Taylor, who moved the motion, worked in South Africa, Peru and with First Nations populations in Canada while attending medical school at the University of Alberta in Edmonton. In each case, he completed all of his predeparture training on his own. He would like to see this type of education become standardized in medical schools.

"You will be prepared in terms of medical knowledge, but maybe not in

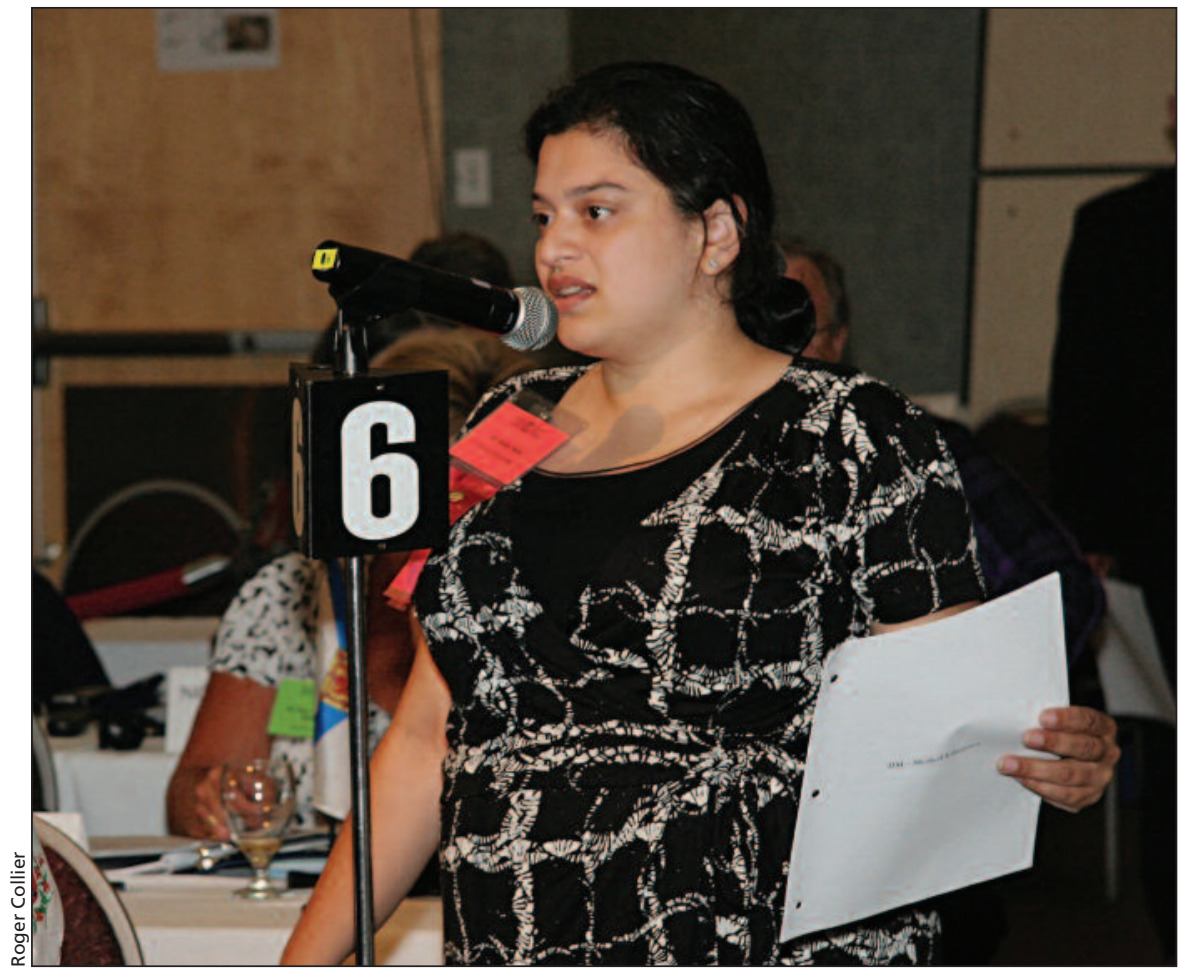

"We need to do education even in the physician group," says pediatrics resident Dr. Roona Sinha. "Global health is not only about students that go on international electives, but it's also about addressing problems within our own marginalized populations and in underserved areas."

terms of language barriers, in term of the cultural and ethical barriers and some of the nuances that you need to know when dealing with underserviced populations. In South Africa, there is a lot of stigma around AIDS. Many people don't understand the science behind the disease. They think it's voodoo. If you don't come in with that background knowledge, and you don't know how to address those types of issues, you are automatically viewed as an outsider," says Taylor, adding that it "all comes back to advocating for patients. How can you do that if you don't know where your patient is coming from?"

Like Sinha, Taylor views the concept of global health as being unrestricted by geography. "If we are really serious about transforming our own health care system, we have to make sure we are pulling up those people that are most marginalized and the most at-risk. It's a global problem that affects millions of people within our own borders."

Most delegates who spoke to the motion were in favour of it. One delegate called it a timely issue and argued that it would enable doctors-in-training to better treat immigrant populations within Canada. Another said there was a "nice overlap between global health and public health" and argued that it was really about studying the social determinants of health. But another voiced concern about the ambiguity of the concept of "global health," while still another worried that the clinical knowledge of medical students might be compromised if yet another topic were added to their already intensive curriculum.

The latter did not concern Dr. Matthew Sheppard, a recent medical graduate from Memorial University of Newfoundland in St. John's. "Contrary 
to what some physicians were saying today, adding global health to the curriculum wouldn't be that difficult. This is something that could be integrated into the curriculum as it stands. You don't have to add extra hours," says Sheppard, adding that "a large part of predeparture training in undergraduate school has been student-driven. We do the best we can, but it would be much better if we could have it ingrained within the medical school."

Motions which met with success at the gathering included one recommending CMA support the rights of patients to be treated equitably and have reasonable access to appropriate care regardless of how their physicians get paid; one calling on CMA to host a conference on physician payment methods in Canada; and one supporting timely access to hospitalization in Canada for those who fall ill or are injured while travelling abroad. - Roger Collier, CMAJ

CMAJ 2011. DOI:10.1503/cmaj.109-3986 